Revista de Literatura, História e Memória

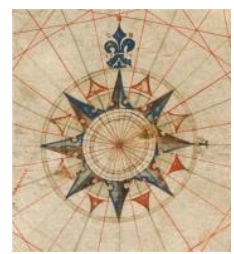

Seção: Pesquisa em Letras no contexto Latino-americano e Literatura, Ensino e Cultura

ISSN 1983-1498

VOL. 17 - Nº 29 - 2021

U N I O E S T E / CA S C A V E L - p. 97-110

\title{
MEMÓRIA, HISTÓRIA E LITERATURA: ESTRATÉGIAS DE CONSTRUÇÃO FICCIONAL E MANUTENÇÃO DA(S) IDENTIDADE(S) NEGRA(S) EM DUAS NARRATIVAS DA LITERATURA BRASILEIRA
}

\author{
Memory, history and literature: strategies of ficcional \\ building and maintenance means of identity of black \\ characters in two brazilian literature narrative
}

\author{
James Rios de Oliveira Santos ${ }^{1}$ \\ Rosiney Aparedecida Lopes do Vale ${ }^{2}$
}

RESUMO: Este artigo objetiva compreender o papel da Memória e da História como estratégias de construção ficcional e como meios de manutenção da(s) identidade(s) dos personagens negros/as que compõem o plano diegético da narrativa infantojuvenil Sortes de Villamor, de Nilma Lacerda, e do conto "Negrinha", de Monteiro Lobato. Ademais, verifica-se, neste trabalho de cunho qualitativo, o modo como a literatura constitui-se e oferece-se como importante instrumento para a transmissão da cultura afro-brasileira, permitindo que a memória coletiva desse povo seja salvaguardado por intermédio desse veículo de comunicação discursiva. Constitui o escopo teórico desta discussão Michael Pollak (1992), Maurice Halbwachs (1990), Gregory Rabassa (1965), Regina Dalcastagnè (2008), dentre outros estudiosos que se debruçam sobre o assunto.

PALAVRAS-CHAVE: Memória; História; Literatura; Identidade Negra.

ABSTRACT: This article aims to understand the role of the Memory and the History as strategies of ficcional building and as identity means of maintenance of black characters that compose the diegetic plan of infancy-youthful narrative: Sortes de Villamor, written by Nilma Lacerda, and the Negrinha short story, by Monteiro Lobato. Furthermore, in this qualitative study, the way in which the literature is composed and offered as an important instrument to transmit the African-Brazilian culture, allowing the discursive communication. The theoric scope of this discussion, is constituted by Michael Pollak (1992), Maurice Halbwachs (1990), Gregory Rabassa (1965), Regina Dalcastagnè (2008) among others researchers who are studying this subject.

KEYWORDS: Memory; History; Literature; Identity.

\section{INTRODUÇÃO}

O que propomos, neste artigo, é uma discussão sobre a representação ${ }^{3}$ da identidade negra na literatura brasileira sob o viés da História e da Memória. Antes, porém, é

\footnotetext{
${ }^{1}$ Aluno do curso de Pós-graduação (Doutorado) em Estudos Literários da Universidade Estadual de Londrina (UEL). Diretor de Cultura da Universidade Estadual do Norte do Paraná.

${ }^{2}$ Professora-Doutora do Departamento de Letras da Universidade Estadual do Norte do Paraná (UENP).

${ }^{3}$ Cientes da complexidade que encerra o vocábulo "representação", termo que constitui-se como um objeto de investigação no campo das Ciências Humanas e da Psicologia social - com Pierre Bourdieu, Roger Chartier, Serge Moscovici, p.e. - e que há uma vasta consideração teórica sobre assunto, esclarecemos que, pelos limites que este artigo nos impõe e pelo caminho teórico que pretendemos percorrer, valemo-nos do termo no sentido em que emprega o dicionário, isto é, o ato ou o efeito de representar.
} 
preciso salientar que uma abordagem sobre esse tema exige, via de regra, um esforço reflexivo que leve em consideração algumas noções conceituais e críticas pertinentes ao campo dos estudos que se dedicam a discutir as questões atinentes às intersecções entre literatura, discurso e raça. Daí a necessidade de contarmos com respaldo de estudiosos que transitam por esta área, como Gregory Rabassa, Teun Van Dijk, Regina Dalcastgnè, dentre outros, que nos ajudarão a formular algumas de nossas hipóteses, a partir de suas respectivas pesquisas.

Para que o interlocutor deste estudo possa melhor compreender o desenvolvimento desta reflexão, é salutar apresentar, logo de antemão, os nossos objetos de análise: o conto "Negrinha", de Monteiro Lobato e a obra Sortes de Villamor, de Nilma Lacerda. O primeiro é um texto pré-modernista; o segundo, uma narrativa infanto-juvenil contemporânea. Ambos os textos apresentam, no fio do discurso ficcional, um recorte da História do Brasil, por onde transita uma multiplicidade de personagens negros que merece uma leitura mais acurada.

A literatura brasileira, seja ela destinada ao público adulto seja ao infanto-juvenil, é um terreno fértil para se problematizar questões tangenciais à representação identitária dos personagens, principalmente a dos negros, uma vez que este campo literário é constituído por autores majoritariamente brancos (DALCASTAGNÈ, 2008), os quais apresentam, no plano diegético de suas obras, diversos actantes ${ }^{4}$ negros que nem sempre tiveram sua identidade preservada, pois foram/são representados, recorrentemente, pela ótica da história brasileira convencionada como oficial (história oficial), que, em suas mais diversas formas de circulação discursiva - livros didáticos, por exemplo - têm apresentado essa comunidade somente a partir de uma perspectiva subalterna ${ }^{5}$.

Este fato também é recorrente na literatura infantojuvenil brasileira, pois, em conformidade com a pesquisa de Fulvia Rosemberg e Paulo Vinicius Baptista da Silva (2012), a representação de personagens negros seguiu na mesma direção da literatura adulta: muitos deles foram estereotipados e apresentados com suposto resgate do folclore, com referências etnocêntricas associadas apenas à "simplicidade, primitivismo, ignorância, meio rural e

\footnotetext{
${ }^{4}$ Emprestamos do semioticista russo, Algirdas Julien Greimas, o termo actante para nos referir aos personagens da narrativa.

${ }^{5} \mathrm{Na}$ obra $O$ negro na ficção brasileira (1965), por exemplo, o professor americano, Gregory Rabassa, com supervisão de Afrânio Coutinho e Celso Cunha, percorre, cronologicamente, a literatura brasileira, com intuito de evidenciar a (não) participação do negro nas mais diversas formas e gêneros literários, revisando uma plêiade de autores que escreveu do Quinhentismo ao Modernismo. Em sua pesquisa, o estudioso constatou que a pessoa negra, enquanto personagem fictício, tem se situado não só à margem da historiografia literária, mas também na periferia temática de romances e outras manifestações em prosa.
} 
passado escravagista, com características corporais animalizadas" (GOUVÊA, 2004, p. 219 apud SILVA e ROSEMBERG, 2012).

A construção desses estereótipos, seja na literatura adulta ou infanto-juvenil, é, em nossa compreensão, fruto de um longo período escravagista que marcou a História brasileira. E se pensarmos nesta História (que subsidiou a criação de obras literárias), grafada com inicial maiúscula, tal qual compreende Halbwaches (1990) e Douek (2003), podemos afirmar que ela se encontra desvinculada da vida concreta de determinadas comunidades, pois

As divisões temporais estabelecidas pela história nada tem a ver com a vida dos grupos, nem com o tempo das gerações: a história coloca-se fora dos grupos e acima deles. Querendo ser objetiva e imparcial, a história interessase apenas pelos fatos independentes do modo pelo qual esses fatos afetaram os grupos vivos e reais (DOUEK, 2003:28, grifo nosso).

Ora, se a História está dissociada das experiências concretas de certas comunidades, e se posiciona acima delas, é justificável que as representações desses personagens, respaldadas nessa instância historiográfica, tendem a distanciar-se de sua identidade e, assim, a sua presença na esfera ficcional, sobremaneira na literatura, estaria marcada pela subalternidade notadamente observável nas relações sociais entre os demais actantes que compõem o plano narrativo. Eis a nossa primeira hipótese.

Por outra via, é consensual, entre alguns estudiosos das Ciências Humanas - dentre eles Stuart Hall (2015) e Maurice Halbwachs (1990) - a assertiva de que a preservação da identidade de um grupo se processa por meio da manutenção de sua tradição. Nessa esteira, as lendas, os costumes e os saberes (medicinais, religiosos etc.), transmitidos principalmente por meio da oralidade, constituem alguns dos muitos mecanismos de perpetuação de uma determinada cultura, que, sob a égide do tempo, tende a inscrever, nas mentes de seus indivíduos, uma memória comum. Consoante às palavras de Douek (2003):

A memória diz respeito à tradição, do latim traditio, isto é, à ação de dar, de entregar, de ensinar, de transmitir, transmissão que ocorre, em geral, oralmente, de pai para filho, de geração em geração, transmissão de fatos, de lendas, costumes, hábitos, práticas, valores, doutrinas, modos de agir e pensar, ensinamentos de determinado grupo social, e que assegura a identidade grupal, ou seja, a continuidade dos traços característicos próprios e fundamentais do grupo (DOUEK, 2003, p. 29).

É esta memória, compartilhada entre os membros de uma mesma comunidade, que também nos interessa nesta discussão, pois se oralmente ela permite salvaguardar identidade(s), aventamos a hipótese de que certas narrativas ficcionais contemporâneas, as 
quais se utilizam da forma escrita como meio de expressão, oferecem-se como novos instrumentos cujos resultados podem ser satisfatórios para tal objetivo. Aliás, advém daí a formulação de nossa segunda hipótese, que também se constituiu a partir de repetidas leituras da obra Sortes de Villamor, de Nilma Lacerda, a qual faz da memória uma estratégia não só para sua construção ficcional, mas também, um mecanismo de preservação da identidade afro-brasileira.

O CONTO "NEGRINHA" NAS LINHAS E NAS ENTRELINHAS: A HISTÓRIA OFICIAL COMO ESTRATÉGIA DE CONSTRUÇÃO FICCIONAL

Em contato com o texto em tela, o leitor atento às noções de história e memória, certamente notará que Lobato, ao fazer uso da primeira para dar origem ao conto, "esquece em definitivo a memória, priorizando os fatos que os historiadores reconstroem a partir de seus conteúdos latentes, dos elementos repetitivos e dos rastros" (DOUEK, 2003, p. 33). É óbvio que não se trata aqui de uma construção científica, subordinada a uma multiplicidade de métodos cujo objetivo reside na criação de uma história oficial, até porque, nestes termos, o texto em apreço deixaria de exercer sua função enquanto produção ficcional, o que não é caso. Contudo, o que propomos, neste estudo, é a observação da apropriação da História (oficial) pelo autor para emoldurar o quadro constituinte do conto "Negrinha", que remonta aos anos pós-abolição, apresentando, na trama, a cruel realidade à qual está submetida Negrinha, uma criança cerceada de todos os direitos, inclusive o do nome.

Detendo-nos apenas no título da obra - o que já é suficiente para uma substancial reflexão -, convém-nos lançar a seguinte pergunta: ao ratificar a forma como Dona Inácia nomeia a protagonista pela cor da sua pele, o narrador também se apropria de um preconceito (ao desumanizar a personagem que nem nome próprio tinha) ou apenas quer enfatizar uma crítica social, isto é, o tratamento desumano que o negro sofria mesmo após abolição?

Narrado em terceira pessoa, o narrador onisciente sabe tudo dos personagens, tanto em seu aspecto físico quanto psicológico. E o que ele não sabe, ele se indaga, pois tem curiosidade em saber mais para poder melhor entendê-los. A título de ilustração, observemos um desses momentos no qual ele se propõe a refletir:

Que ideia faria de si essa criança que nunca ouvira uma palavra de carinho? Pestinha, diabo, coruja, barata descascada, bruxa, pata-choca, pinto gorado, mosca morta, sujeita bisca, trapo, cachorrinha, coisa ruim, lixo - não tinha conta o número de apelidos com que a mimoseavam (LOBATO, 2008, p. 21). 
Ora, sabendo tanto, era de se esperar que o narrador soubesse o nome da órfã. No texto, porém, não há indícios de que saiba. Portanto, ou ele sabe, mas quer evidenciar o descaso humano e social no qual está inserida a personagem e, por isso, oculta o nome, pois ocultando-o, salienta, ratifica a insignificância humana, social da personagem; ou realmente não sabe e, por sua vez, preocupa-se em apenas narrar os fatos a partir de um olhar distante, mantendo-se propositadamente de fora - como faz um historiador no processo de elaboração da História, conforme as considerações de Douek (2003).

Se a escolha feita pelo narrador está relacionada à primeira possibilidade suscitada acima, podemos presumir que por detrás da mão desse narrador encontra-se a mão de um autor preocupado com a situação social do seu país e conscientemente disposto a registrar e criticar literariamente aquela sociedade. Se, todavia ele sabe o nome da personagem mas ainda assim utiliza o termo Negrinha é porque não está preocupado em mostrar que negro tem nome, mantendo-se alheio a quaisquer outros elementos que não os vistos. Nessa perspectiva, podemos afirmar que esse narrador está preocupado sim, até certo ponto, com os problemas sociais, mas que traz em si resquícios racistas. Discrimina, pois, mesmo sabendo o nome da personagem, opta por ignorá-lo, crendo, muito possivelmente, ser desnecessário dar um nome, em particular, a uma criança negra- ainda que esse mesmo narrador não tenha nomeado as sobrinhas de Dona Inácia. Estas, porém, não tem dentro do texto o mesmo espaço, o que poderia justificar a ausência do nome.

É preciso considerar ainda uma terceira possibilidade: a de uma representação social que imperava naquele contexto histórico, pois é sabido que crianças negras eram comumente chamadas de "Negrinhos", "Negrinhas" pelos donos de escravos. E embora findada a escravidão, como já comentado anteriormente, os ventos republicanos em nada contribuíram naqueles primeiros anos para uma melhora significativa e relevante na e para a vida dos negros no Brasil, visto que ser livre pressupõe, além do direito de ir e vir, dignidade, respeito, trabalho e educação - itens que não foram considerados, pensados e proporcionados para os negros recém-libertos. Além disso, esse "novo" contexto não retirou imediatamente vícios antigos em relação ao tratamento para com os/as negros/as.

Considerando qualquer uma das três possibilidades interpretativas suscitadas acima, é de nosso entendimento que apenas a utilização da História como estratégia de construção ficcional - nos referimos aqui especificamente à representação da comunidade negra, que tem inscrita nos corpos de seus membros as marcas da escravidão - implica um modo representativo muito aquém daquilo que o autor poderia subtrair de todos os valores presentes no seio da cultura negra, podendo acessá-los, inclusive, por meio da memória coletiva desse 
grupo.

Desse modo, uma representação calcada nos moldes da História tende a ser, no mínimo, nebulosa, pois, nesse caso, o discurso literário não está livre de apresentar vestígios racistas, conforme se pôde observar anteriormente, e tende a apresentar o negro apenas sobre o prisma da subalternidade (como nos excertos que seguem), ainda que se possa notar, na voz de quem enuncia, um quê de denúncia social. "Nascera na senzala, de mãe escrava, e seus primeiros anos vivera-os pelos cantos escuros da cozinha, sobre velha esteira e trapos imundos" (LOBATO, 2008, p. 01). E prossegue o narrador:

Assim cresceu Negrinha - magra, atrofiada, com os olhos eternamente assustados. Órfã aos quatro anos, por ali ficou feito gato sem dono, levada a pontapés. Não compreendia a idéia dos grandes. Batiam-lhe sempre, por ação ou omissão. A mesma coisa, o mesmo ato, a mesma palavra provocava ora risadas, ora castigos. Aprendeu a andar, mas quase não andava. Com pretextos de que às soltas reinaria no quintal, estragando as plantas, a boa senhora punha-a na sala, ao pé de si, num desvão da porta.

- Sentadinha aí, e bico, hein? Negrinha imobilizava-se no canto horas e horas.

—Braços cruzados já, diabo. (LOBATO, 2008, p. 01).

Observa-se que Negrinha foi uma vítima que sofre inúmeros maus tratos e a quem é negado inclusive o direito de se manifestar oralmente. Silenciada e agredida ela nada pode fazer para se defender de seus agressores, cuja violência física e moral fica patente no trecho transcrito acima, comprovando que tais atitudes eram habituais no período histórico em apreço. Para endossar a leitura que temos proposto, é digna de nota uma importante contribuição de Halbwachs (1990:138), o qual acentua que a "história pretende dar conta das transformações sociais da sociedade" e assume, por esta e outras razões, um caráter informativo. Aplicando a consideração do teórico ao conto ora analisado, observamos que ela vai ao encontro de nossa discussão, pois o que se observa no pano de fundo da narrativa literária é justamente esse desenrolar de ocorrências de ordem social: o período pós-abolição e, por conseguinte, o momento em que sucedeu a constituição da República. Esses acontecimentos, vale lembrar, são resgatados por monteiro Lobato a título de informação para compor o plano diegético e podem ser observadas sem muito esforço pelo leitor:

A excelente dona Inácia era mestra na arte de judiar de crianças. Vinha da escravidão, fora senhora de escravos - e daquelas ferozes, amigas de ouvir cantar o bolo e estalar o bacalhau. Nunca se afizera ao regime novo - essa indecência de negro igual a branco e qualquer coisinha: a polícia! "Qualquer coisinha": uma mucama assada ao forno porque se engraçou dela o senhor; uma novena de relho porque disse: "Como é ruim, a sinhá!"... O 13 de Maio 
tirou-lhe das mãos o azorrague, mas não the tirou da alma a gana (LOBATO, 2008, p. 02, grifo nosso).

Conforme registram James Rios de Oliveira Santos e Tiago Angelo (2014), o conto "Negrinha" é daqueles textos cujo vigor narrativo, a transparências dos fatos, o ardor do grotesco, o encadeamento dramático, ensejam uma boa reflexão sobre um dado período da sociedade brasileira. Reflexão esta que nos permitiu entrever o quanto custa o resgate da História pela Literatura quando o objeto de representação é a personagem negra.

No curso da reflexão exposta, não foi nossa intenção desqualificar a obra, tampouco o seu autor, até porque este, convém lembrar, no entendimento do crítico literário Alfredo Bosi (2006, p. 216-217), foi um "escritor de outro estofo: sabia narrar com brilho um caso, uma anedota e, sobretudo um desfecho de acaso ou violência”. A nossa insistência, portanto, reside na compreensão de que utilização a História, principalmente aquela elaborada a partir do ponto de vista dominante (DOUEK, p. 2003), não atinge a mesma magnitude de uma representação calcada nos aspectos concernentes à memória, que, por meio de seus próprios mecanismos, retira da seiva de um grupo, o nutriente necessário para perpetuação da tradição e ratificação de sua identidade - o que seria mais coerente para livrar a população negra dos grilhões da escravidão, pelo menos em termos de representação ficcional.

\section{A MEMÓRIA COMO ESTRATÉGIA DE PRESERVAÇÃO DE IDENTIDADE(S) EM SORTES DE VILLAMOR}

Antes de avançar em nossa discussão com maior propriedade, é de suma importância ressaltar que a elaboração de uma narrativa centrada nas questões étnico-raciais é quase sempre um desafio que se interpõe entre autor e a obra, porque, conforme mencionado anteriormente, o campo literário brasileiro é, por uma questão histórica, constituído predominantemente por autores brancos, o que implica, logicamente, em termos de representação. Do Romantismo ao Modernismo, lembra Gregory Rabassa (1965), muitos foram os autores - bem intencionados, diga-se de passagem - que se dedicaram a tal empreitada e acabaram por cair em armadilhas representativas, visto que o modo como muitos personagens negros foram dispostos em suas construções literárias, quando não representados de maneira subalterna, foram enquadrados em certas situações em que a sua realidade concreta foi encoberta (RABASSA, 1965). A questão, como se percebe, é emblemática e exige cautela.

Não há, obviamente, um roteiro pronto e acabado a ser seguido pelo escritor que o 
isentará de tais armadilhas ou que o levará a lograr êxito em uma representação coerente. No entanto, há outras estratégias de construção ficcional (e a memória é uma delas) que tendem a trabalhar a identidade negra de modo que a vivência cultural e as tradições dessa comunidade sejam valorizadas. Desse modo, trabalhar a memória como meio de criação artística é ratificar "uma identificação direta com passado, passado vivo, carregado pelos grupos vivos, unindoos e assegurando sua identidade" (DOUEK, 2003, p. 34). E é justamente isto que faz Nilma Lacerda, em sua obra Sortes de Villamor.

Constituída por meio de uma linguagem acessível ao público a que se destina, o texto em análise é uma narrativa histórica dividida em seis capítulos, um epílogo e alguns apêndices, os quais servem de referências para o leitor situar-se no tempo e no espaço onde a trama se passa, isto é, no início do século XIX, na cidade de Salvador, Bahia. O enredo apresenta a história de Caim de Node e de uma jovem francesa, Blanche de Villamor - ou simplesmente Branca - que, após o naufrágio de seu navio, foi recebida por Ismê Catureba em sua casa, sendo "acolhida, de cura e predileção" (LACERDA, 2013, p. 178).

A autora não constrói seus personagens negros de maneira estereotipada, tampouco apresenta marcas linguísticas que possam aludir a alguma forma de preconceito, racismo. Caim, por exemplo, é um personagem liberto da escravidão que conduz o texto como narrador, não hesitando em incluir, na história em que narra, a sua própria história, que se confunde com a memória de seu grupo social.

Minha mente ia para as batalhas, voltava no tempo, libertava Palmares, salvava Zumbi. Avançava no tempo para ser o guerreiro mais ousado, mais experiente, capaz de conduzir o meu povo à liberdade, de fazê-lo regressar ao corpo de nossa mãe, à fala de nossas nações (LACERDA, 2013, p. 3132 , grifo nosso).

É bem verdade que o passado escravista também constitui o pano de fundo dessa narrativa. Todavia, a autora da obra foge do modelo "pobre escravo da senzala", resgatando a história dos escravizados e ex-escravizados a partir de uma perspectiva positiva, envolvendoos "em sua realidade social" (DALCASTAGNÈ, 2008:101). Nesse sentido, Nilma Lacerda (2013) recupera, por meio de Caim, a memória de Zumbi dos Palmares, um dos maiores líderes quilombola. Temporalmente, Caim está distante de Zumbi, uma vez que, segundo dados históricos, aquele se situa no século XIX, enquanto este no século XVII - conforme aponta a trama. Obviamente, o personagem da escritora contemporânea não esteve em contato com herói negro, pois os dois pertenceram a "espaços-tempos" diferentes. O que ocorre aqui é, na compreensão de Michael Pollak (1992, p. 02), um acontecimento vivido por "tabela", 
um "fenômeno de projeção ou identificação com determinado passado, tão forte que podemos falar numa memória quase que herdada".

O protagonista, conforme se observou no excerto acima, identifica-se de maneira assídua com a sua comunidade, o que justifica o seu desejo pungente de voltar no tempo e lutar por Palmares. Levando em conta, ainda, as considerações de Michael Pollak (1992), podemos afirmar que a memória herdada por Caim, que se remete aos tempos das grandes batalhas ocorridas nas adjacências dos quilombos, afere a ele a possibilidade de não só se deslocar no tempo, mas de rememorar, por meio de sua imaginação, o fato ocorrido, a tal ponto de confundir o leitor sobre essa possibilidade, pois os acontecimentos rememorados por tabela "são acontecimentos dos quais nem sempre a pessoa participou, mas que no imaginário, tomaram relevo que, no fim das contas, é quase impossível que ela consiga saber se participou ou não" (POLLAK, 1992, p.02).

Embora o texto em análise não seja uma narrativa memorialística, não se pode negar, por outro lado, que por detrás da voz do narrador-protagonista, há uma autora preocupada em recuperar a identidade por meio da memória, com intuito de subtrair as melhores experiências do povo negro em diversas frentes. O modo como Caim de Node é representado no excerto abaixo, por exemplo, permite ao leitor entrever a pró-atividade do personagem que se opõem veementemente ao sistema escravocrata, evidenciando que a resistência constitui um valor a ser prezado entre os membros dessa comunidade. Esse fato, é importante destacar, adquire maior relevo quando se nota a mobilização da memória de Caim pela autora, a fim de reestabelecer as lembranças relacionadas às lutas dos escravos angolanos e congolenses, muitos deles mortos em batalha no quilombo dos Kalunga.

Não saí sem destino. Me embrenhei pelo sertão, caminhei em direção ao quilombo dos Kalunga, um povo que sempre foi elogiado pela consciência da liberdade e reverência dos ancestrais. Vindos quase todos do Congo ou da Angola, consideravam que se render à escravidão era trair a memória dos que os antecederam e procuravam preservar os costumes e ritos da terra deixada para trás (LACERDA, 2013, p. 116, grifo nosso).

O excerto acima ainda abre margem para discussão de outro aspecto importante: a questão do pertencimento. Não é novidade que muitas pessoas negras (de diferentes etnias), oriundas de diversos países da África, foram submetidas, no início do século XVI, à escravidão no Brasil. Longe, portanto, de suas terras natais, tais sujeitos, sobrepostos a uma mesma situação (a de servidão), buscavam na memória herdada de seus entes passados o elo que os liga a seus países de origem, de onde subjazem os elementos que compõem seus 
respectivos sistemas culturais. Isto implica no fato de que um indivíduo, ainda que esteja fisicamente distante de sua terra-mãe, tenha a possibilidade de revisitar suas origens sem ao menos ter que se deslocar até ela.

Pensando isso em termos ficcionais, podemos notar que o texto em tela não nos apresenta indícios da naturalidade do protagonista, contudo, há uma passagem em que é possível observar o sentimento de pertencimento as duas nações concomitantemente, sem ao menos conhecê-las fisicamente: "Com as apresentações feitas, tivemos uma roda de tambores de nossa Angola, de nosso Congo. Tomamos cachaça e aluá, para dormir felizes, a cabeça posta em nossa terra, que a gente visitava voando por cima do mar, no tempo escuro da noite" (LACERDA, 2013, p. 117). Esse fenômeno pode ser explicado se considerarmos a proposição de Pollak (1992, p. 03), o qual postula que os locais longínquos - nesse caso Angola e Congo - "fora do espaço da vida de uma pessoa, podem constituir lugar importante para a memória do grupo, e, por conseguinte, da própria pessoa, seja por tabela, seja por pertencimento a esse grupo".

Para finalizar a nossa reflexão acerca de Caim de Node, podemos afirmar que este é um personagem muito lúcido em relação ao contexto social em que se insere, já que discute, por vários momentos, a diáspora negra - processo pelo qual muitos africanos, de diversas etnias, forçosamente passaram. "Somos almas arrancadas do corpo. Deixamos para trás o corpo da mãe, a África que nos deu a negrura da pele, esse nariz tão largo, o colchão de ar nos cabelos e fomos depositados em terras que não careciam de filhos como nós" (LACERDA, 2013, p. 27, grifo nosso). Ao dar vida a um personagem como esse, Lacerda avança e muito, em termos de representação, em relação a muitos escritores, dentre eles Monteiro Lobato, que deu origem à Negrinha a partir de uma perspectiva historiográfica, sem adentrar nas especificidades identitárias. Esta atitude, vale acentuar, é quase sempre justificada com o suposto e "pretenso realismo" da obra, "na ilusão de que o escritor toma seus modelos diretamente da realidade histórica, e não que lida com outras representações" (DALCASTAGNÈ, 2008, p. 106).

Não há como refletir coerentemente sobre a cultura negra, ainda que numa perspectiva ficcional, sem considerar as suas especificidades, como a culinária, a dança, o canto, os saberes transmitidos oralmente, a integração do homem à natureza etc., pois, em nossa compreensão, tais particularidades, quando abordadas em conjunto, permitem ao leitor (re)conhecer substancialmente uma cultura que se manifesta por diversos meios. E Nilma Lacerda, enquanto autora compromissada com a preservação de uma identidade cultural, utiliza tais particularidades como estratégia de construção ficcional, principalmente quando dá 
vida à Ismê Catureba, uma personagem negra que mantém viva, em suas práticas cotidianas, as tradições herdadas de seus antepassados africanos, quer pelo cultivo das ervas, quer pela manutenção do Calundu - religião que se assemelha ao Candomblé.

Ismê conhecia a erva para cada mal ou para cada bem. Colhia folha ou raiz na hora certa, sabia dos preparos adequados, da forma de macerar, secar ou ferver. Não cobrava pelos serviços, as pessoas pagavam o valor do bem recebido. Mas Ismê ouvia também os ventos. Ouvia os ventos e ditava destinos da gente (LACERDA, 2013, p. 43).

É de nosso conhecimento que as religiões de matriz africana constituem-se como um dos pilares da cultura afro-brasileira, e, por isso, entendemos que uma representação (da identidade negra), que se pretenda factível, não poderia deixar de apresentar, sob o tecido ficcional, essa relação intrínseca entre cultura e religião. São vários os momentos em que o Calundu ganha relevo na narrativa de Nilma Lacerda, como no extrato acima. E este relevo justifica-se pelo fato de a autora descrever substancialmente as cenas dos cultos religiosos, inserindo-os em sua realidade concreta - tal como propõe Dalcastagnè (2008) -, com o objetivo de assegurar a identidade religiosa por meio de sua transmissão entre os indivíduos das comunidades.

De acordo com Halbwachs (1991, p. 71), “toda religião implica uma mobilização específica da memória coletiva [...]”, e, "na base de toda crença religiosa existe efetivamente crença na continuidade da descendência da fé". Consoante ao postulado do teórico francês, podemos justificar a necessidade manifesta de Ismê em dar continuidade à sua tradição religiosa, por meio de Branca de Villamor.

Ismê não tinha filhos de sangue, e cada vez que olhava para Branca de forma amorosa, que cuidava de branca com um cuidado maior que dado às outras meninas, sentia estar traindo os ancestrais. Traía e traía de novo, porque não fazia esforço para deixar de gostar dela, para expulsar do peito aquele afeto tão sem razão. Quando o sopro do vento veio e disse "Branca herda a casa", a alma de Ismê pareceu perder a âncora do corpo (LACERDA, 2013, p. 4748).

Conforme propõe a passagem acima, estamos diante de duas personagens provenientes de contextos culturais distintos, as quais, certamente, não compartilharam dos mesmos costumes, tampouco da mesma memória (coletiva), que exerce um papel essencial na ratificação das identidades, pois, se "podemos dizer que, em todos os níveis, a memória é um fenômeno construído social e individualmente, quando se trata da memória herdada, podemos também dizer que há uma ligação fenomenológica muito estreita entre a memória e o 
sentimento de identidade (POLLAK, 1992, p. 05)

Portanto, se há uma relação íntima entre memória e identidade, tal qual afirma Michael Pollak, podemos compreender melhor o fato de Branca não aceitar seguir os preceitos africanos, visto que, embora se note um vínculo afetivo entre ela e Ismê, a jovem de Villamor nasceu na França - um país recipiente e propagador dos ideais iluministas pelo mundo ocidental -, o que justifica seu ceticismo perante as crenças religiosas de matriz africana, conforme o excerto que segue:

Éclair, foudre, tonnerre: relâmpago, raio, trovão. A tempestade vem, temos que rezar, invocar os santos ou as entidades. Digo isso à Branca. Ela sacode a cabeça, não e não. Diz: Meu pai me fez esquecer isso de rezar, me fez saber trocar as tempestades dentro da gente por outras coisas (LACERDA, 2013, p, 56).

As diferenças culturais, embora elevem o clímax da narrativa num primeiro momento, evidenciam, em outras partes do texto, que a tolerância constitui a máxima da obra, pois a personagem Branca, em todos os momentos em que fora representada no plano diegético, postou-se de maneira respeitosa em relação à senhora Catureba. Fato este que pode ser observado no fragmento a seguir, em que o narrador, ao resgatar as memórias da jovem francesa - marcadas pelas sombrias recordações da inquisição - permite ao leitor entrever o temor que esta sente em relação a uma possível morte da curandeira, justificando todo o seu afeto para com ela:

Branca me explicou que tinha medo, la peur, la peur. Não queria ser como Ismê, na terra dela muita gente era queimada na fogueira porque mexia com essas coisas. Não acreditava em bruxas, les sorcières era apenas as mulheres que sabiam dos segredos da natureza e os usavam para curar uns males, para causar outros, talvez. Mas a maior parte das pessoas via um perigo nessas mulheres e por isso muitas eram presas, condenadas à morte. Não queria isso, de jeito nenhum (LACERDA, 2013, p. 49).

Sortes de Villamor é uma narrativa leve. Leve porque foi elaborada ao sabor de um tempo-passado reconstruído por meio das memórias de uma coletividade. Diante dessa reconstrução, encontra-se uma autora preocupada com as questões identitárias e, por isso, apresenta ao leitor uma nova perspectiva de se plasmar os/as personagens negro/as no plano narrativo. Mesmo quando estes estão dispostos na diegese junto de outros actantes de cor branca, conforme a passagem acima, a superioridade racial (branca) - notadamente perceptível no conto "Negrinha", por exemplo - é encoberta para dar vazão a uma relação amistosa, afetiva, em que o leitor, principalmente aquele em formação, tem a oportunidade de 
rememorar o passado sob um outro viés que não aquele recorrentemente apresentado pela história oficial.

\section{CONSIDERAÇÕES FINAIS}

Quando nos propusemos a discutir História e Memória por meio da Literatura, sabíamos do esforço que teríamos de fazer para não cometermos o equívoco de conjugar os aspectos concernentes às duas primeiras "disciplinas", já que estes termos (história e memória) "assumem suas especificidades e bifurcam-se num desencontro" que levou, após alguns séculos de discussões, "a um verdadeiro divórcio entre as partes" (DOUEK, 2003, p. 26). Acreditamos, portanto, que o nosso esforço reflexivo foi capaz de apresentar não apenas esse distanciamento, mas, sobretudo, de compreender o efeito que uma e outra exerce, sob o tecido ficcional literário, em termos de representação.

A representação da identidade afro-brasileira na esfera literária constitui-se como um veio de relevância a ser colocada em discussão em diferentes frentes, principalmente no âmbito acadêmico, pois a literatura, em suas mais diversas formas de expressão, é, como lembra Van Dijk (2012, p. 15), um potencial veículo de comunicação discursiva - meio pelo qual "a maioria dos membros dos grupos dominantes aprende a ser racista". Nessa perspectiva em que fala o teórico, é de nosso entendimento que as obras as quais se utilizam da história oficial como estratégia de construção ficcional tendem, em maior ou menor grau, formar leitores indiferentes à invisibilidade, à subalternidade da pessoa negra. E excedendo os limites da ficção, corre-se o risco de que tais indivíduos tendam, também, a assumir posicionamentos racistas em suas relações sociais, ainda que de maneira inconsciente.

Em linhas gerais, o conto "Negrinha" é uma narrativa já conhecida e consagrada pela crítica, quer por seu vigor narrativo, quer pelo encadeamento das ações que aferem primor a todo o conjunto da obra. E ainda que se note um quê de denúncia social na voz do narrador, a construção diegética de Monteiro Lobato seguiu os modelos representativos fornecidos pela história oficial, a qual tem posicionado os personagens negros a partir da perspectiva que temos defendido até aqui. Por sua vez, Sortes de Villamor constitui o oposto do texto lobatiano não só porque insere suas personagens em suas realidades concretas, mas, também, pelo fato de haver, por de trás de uma complexa e bem delineada sintaxe narrativa, uma escritora preocupada em manter a identidade de seus personagens por meio de sua(s) memória(s); e por possuir uma consciência avessa à ideia de se abordar "a história dos negros a partir da escravidão ou apresentar o continente africano estereotipado e exótico" 
(BONICCI, 2011, p. 5, grifo nosso).

\section{REFERÊNCIAS}

BOSI, A. História Concisa da Literatura Brasileira. 43 ed. São Paulo: Cultrix, 2006.

BONNICI, T. Multiculturalismo e Diferença: Narrativas do sujeito na literatura negra britânica e em outras literaturas. Maringá: Eduem, 2011.

DALCASTAGNÈ, R."Entre silêncios e estereótipos: as relações raciais na literatura brasileira contemporânea". Estudos de literatura brasileira contemporânea, n 31 . Brasília, janeirojunho de 2008.

DOUEK, Sybil. Memória e exílio. São Paulo. Escuta, 2003.

LACERDA, Nilma. Sortes de Villamor. 1 ed. São Paulo: Scipione, 2013.

LOBATO, Monteiro. Negrinha. São Paulo: Brasiliense, 2005.

HALBWACHS, Maurice. A Memória Coletiva. Trad. Laurent León Schaffter. São Paulo: Revista dos Tribunais, 1990.

HALL, Stuart. A identidade cultural na pós-modernidade. Trad. Tomaz Tadeu Silva. Rio de Janeiro: Lamparina, 2015.

POLLAK, Michael. Memória e identidade social. In: Estudos Históricos, Rio de Janeiro, vol.5, n.10, p. 200-212, 1992.

RABASSA, Gregory. O negro na ficção brasileira. Trad: Ana Maria Martins. Rio de Janeiro: Tempo Brasileiro, 1965.

SANTOS, James; ANGELO, Tiago. O conto Negrinha nas linhas e nas entrelinhas: Um diálogo entre a literatura e a história. Claraboia, Jacarezinho, n.2/1, p.98-107, jan/jun, 2015.

SILVA, Paulo; ROSEMBERG, Fulvia. "Brasil: Lugares de Negros e de Brancos na Mídia". In: VAN DIJK, T, A. (ORG) Racismo e Discurso na América Latina. 2. ed. São Paulo: Contexto, 2012.

VAN DIJK, Teun, A. Racismo e Discurso na América Latina. 2. ed. São Paulo: Contexto, 2012. 